\title{
Virtual simulation of production line for ergonomics evaluation
}

\author{
Ming Chen · Jin-Fei Liu
}

Received: 30 December 2013/Accepted: 27 January 2014/Published online: 4 March 2014

(C) Shanghai University and Springer-Verlag Berlin Heidelberg 2014

\begin{abstract}
To avoid ergonomic problems in the early planning stages of a production line and achieve more satisfactory planning and design, ergonomic simulation is particularly important in digital production line planning. An ergonomics analysis method is presented by using two theories: Ovako working posture analysis system (OWAS) and Burandt-Schultetus hand-arm force analysis (BSHA). The processes of ergonomics analysis and simulation are discussed based on a platform of process simulation and process designer. As an example, the paper shows how ergonomics problems are considered in production line planning to make a better choice between different production line planning schemes.
\end{abstract}

Keywords Ergonomics - Production line planning · Process simulation and optimization

\section{Introduction}

In the today's fast paced world, life cycle management, cost control strategy and virtual simulation method become more and more significant for enterprises to enhance the competitive power unceasingly. Consequently, independence and short-term design and manufacturing need to be considered within the whole manufacturing system planning and design. Meanwhile production line planning is the key technical issue

\section{Chen}

Sino-German College of Applied Sciences, Tongji University, Shanghai 201804, People's Republic of China

\section{J.-F. Liu ( $\square)$}

School of Electronics and Information Engineering, Tongji University, Shanghai 201804, People's Republic of China

e-mail: jinfeil@tongji.edu.cn to achieve optimal production. To design a new production line or modify one old production line, it is necessary to plan and simulate the manufacturing process. If the assembly line planning is unqualified, it will not only waste labor and resources, but sometimes affect the quantity of products [1]. To avoid the ergonomic problems in the early planning stages of production line, and achieve a more satisfactory planning and design, ergonomic simulation is particularly important in digital production line environment $[2,3]$.

The so-called ergonomics, which is the application of anthropometry, body mechanics, work physiology, psychology and other discipline working methods, structure and function of the characteristics of human research, provides various parts of the body size, weight, body surface area, the proportion of the various parts of the body center of gravity and the relationship between the activities and scope of the human body. Its goal is to offer power range for various parts of the body, the action of the habits of human body parameters, and analyze the human vision, hearing, touch and skin feel characteristics such as the function of sensory organs, the physiological changes during labor, energy consumption, fatigue mechanism of various labor and human abilities to adapt to the load, and the factors that affect mental state psychologically on the efficiency and so on [4-7].

Developing ergonomics in early stages of production system simulation is increasingly recognized as an essential step towards achieving healthy and sustainable production systems. According to Laitila, the capacity of digital human modeling (DHM) to assess ergonomics has increased significantly in recent years $[8,9]$. As a result, DHM tools are increasingly used to identify the potentially harmful working postures, forces and durations which can lead to work-related musculoskeletal disorders. These in turn can result in company costs for worker replacement, compensation and rehabilitation [10-12]. In addition, Falck et al. [13, 14] 
demonstrated a relationship between poor ergonomics and reduced product quality, and emphasized an imperative need for a holistic approach to ergonomics development. Subsequently, ergonomics development in parallel to other aspects of production line planning can increase economical efficiency for companies because more efficient task allocation reduces costs for staff turnover or sick-leave absenteeism $[15,16]$, and prevents the potential reduced-quality production caused by poor workplace ergonomics [17]. Through analyzing and developing production ergonomics, a number of analysis methods can be applied. These methods are, for example, task analysis [18, 19], cognitive work analysis [20], contextual design [21], usability testing [22], heuristic usability evaluations, ergonomics analyses [23], and participatory design [24].

The above researches provide many valuable thoughts and methodologies, but the problems with on-the-job of operators which require the motor skills to do online work have not been further studied. Moreover, in virtual environment, the human body model is rational for the overall design of the production line, the comfort, and the visibility. The accessibility of workers to operate should be further simulated and evaluated.

This paper introduces the background theory of ergonomics analysis, discusses how to consider the ergonomics problems in production line planning, and proposes a new method to make a choice between different production line planning schemes. Finally, cases of product line planning and simulation are discussed using the simulation system of process simulation and process designer.

\section{Ergonomics theory}

Ergonomics is the science of adapting the job and/or the equipment and the human to each other for optimal safety and productivity. The designing machines, tools, and work environment need to accommodate human performance and behaviour best. It is the process of changing the work environment (equipment, furniture, pace of work, etc.) to fit the physical requirements and limitations of employees, rather than forcing workers to adapt to jobs over time which has a debilitating effect on their physical well-being. Companies of all types and scales have increasingly recognized that establishing an ergonomically sensitive work environment for employees can produce bottom-line benefits in cutting absenteeism, reducing health care costs, and increasing productivity. The most advantage of these firms is that they have taken steps to modify the condition (whether in a shop floor or an office) to better fit the physical needs and abilities of workers after carefully analyzing the production condition and the tasks that their employees provide.
Table 1 OWAS fatigue grade

\begin{tabular}{lllll}
\hline Grade & 1 & 2 & 3 & 4 \\
\hline Description & $\begin{array}{c}\text { No } \\
\text { injury }\end{array}$ & $\begin{array}{c}\text { Slight } \\
\text { injury }\end{array}$ & $\begin{array}{c}\text { Moderate } \\
\text { injury }\end{array}$ & $\begin{array}{c}\text { Serious } \\
\text { injury }\end{array}$ \\
\hline
\end{tabular}

There are more than 60 kinds of ergonomic theories, such as static force analysis, low back stress analysis, posture analysis, domain analysis, fatigue recovery analysis, comfort analysis, NIOSH analysis, RULA attitude analysis, Ovako working-posture analyzing system (OWAS) analysis, and so on. Two ergonomic theories of the latest popular theories are shown as follows [25].

\subsection{OWAS based on human operating posture}

OWAS is used to assess posture grade according to the severity of musculoskeletal injuries by posture. Then it will provide the reference to researchers to improve the work situation and environment. OWAS is regarded as the most effective human-computer analysis method to simulate numerous operating positions of various scenes, and is widely used in the industrial fields [26].

By recording the operator's posture, OWAS can evaluate the rationality of posture to change the work environment (equipment, furniture, pace of work, etc.) to fit the physical requirements and limitations of employees. OWAS also can analyze the major posture element of the four parts of human such as back, arms, legs, head and the weight-bearing element, and make use of coded manner to describe the severity of musculoskeletal injuries. By analyzing the interaction of five elements, the fatigue grade of the human body posture can be obtained (see Table 1).

\subsection{BSHA based on human hand-arm}

Burandt-Schultetus hand-arm analysis (BSHA) is used to calculate the maximum permissible load of the human body with one hand snatch jobs-arm. To compare with the actual load, the safety of one-hand operation job will be judged. There are four factors in BSHA analysis including human factors, operating parameters, load parameters and actual load size.

Human factors include gender $\left(P_{1}\right.$, male 1.0 , female $0.65)$, age $(0.80-0.65)$ and trained degree $\left(P_{2}\right.$, average 1.0 , better 1.2, best 1.4). Operating parameters include operation style, working frequency, time and arm posture. Load parameters include load direction, lifting height, forearm posture, the angle between upper-arm and forearm.

According to the above factors, the maximum load of hand-arm system can be described as

$F_{\text {per }}=\left(P_{1} P_{2} \min \left(T_{\text {dyn }}, T_{\text {lim }}\right) F_{\text {max }}\right)$. 


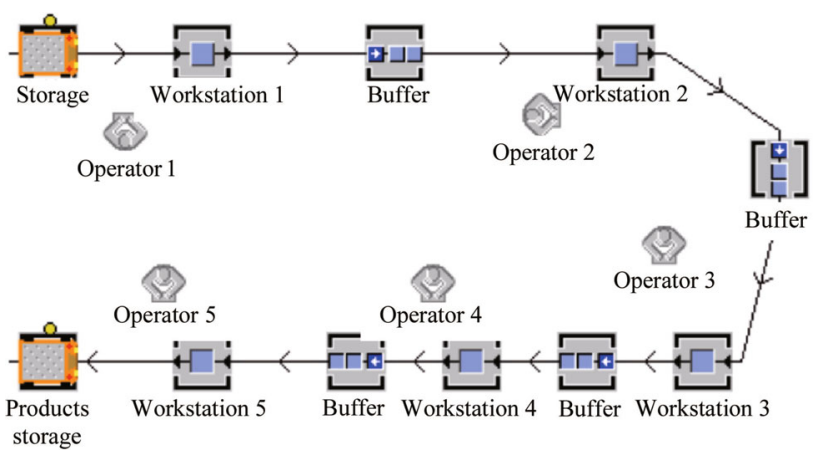

Fig. 1 Model of U-shaped production line

Table 2 Operating time of workstations

\begin{tabular}{lccl}
\hline \multirow{2}{*}{ No. of workstations } & \multicolumn{2}{l}{ Time/s } & \\
\cline { 2 - 4 } & Loading & Unloated & Machining \\
\hline 1 & 9.6 & 8.3 & 28.9 \\
2 & 10.4 & 9.6 & 10.2 \\
3 & 5.6 & 5.3 & 34.7 \\
4 & 11.5 & 10.2 & 30.3 \\
5 & 5.6 & 3.3 & 13.2 \\
\hline
\end{tabular}

When the load is more than $F_{\text {per, }}$, it means that the operation maybe make human-body damage, which is necessary to modify the operation posture. Thus, BSHA is effective to overcome this problem.

\section{Ergonomics problem description}

This production line uses process designer to organize and manage process resource and process simulation to model, simulate and optimize the manufacturing process. This line does not have fully automated manufacturing capabilities, where many workstations need to be manually operated. The mode of U-shaped production line and model including five workstations is shown in Fig. 1.

Operator 1 gets the work-piece from the former storage point 1 , assembles or manufactures work-piece in workstation 1, and then transfers the work-piece to buffer. The works of operators $2,3,4$, and 5 are similar to operator 1 . The loading time, unloated time and machining time are shown in Table 2.

\section{Ergonomics simulation}

This paper uses the Tecnomatix platform of Siemens PLM software to achieve the ergonomics modeling, simulation

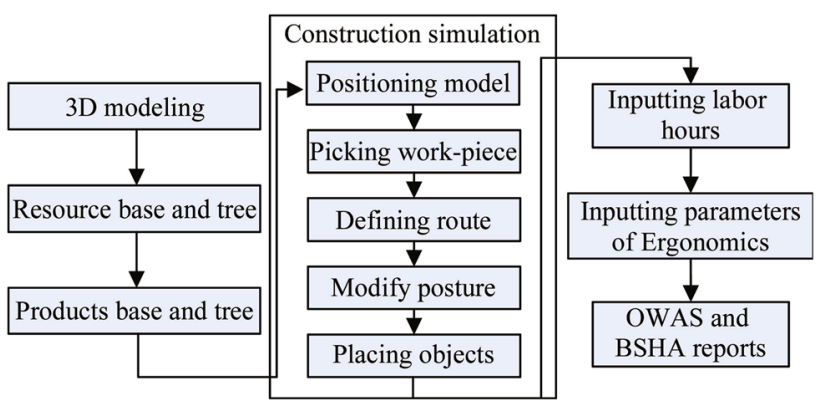

Fig. 2 Flow of ergonomics simulation

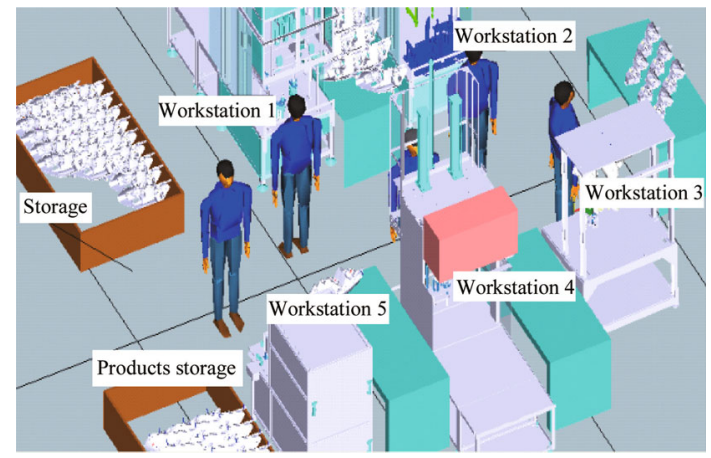

Fig. 3 Layout of U-shaped production line

and optimization. The process designer and process simulation are the two parts of Tecnomatix platform. Process designer is used to organize and manage the resource and process, and process simulation provides the design, analysis, simulation and optimization of workstation. The ergonomics simulation flow is shown in Fig. 2.

Ergonomics modeling uses 3D modeling software to build the 3D model of work piece, and then transfers to cojt or co file. Because the manufacturing system is nonlinear discrete system, it is necessary to built product model, resource model (manufacturing equipment, raw materials, etc.), process model (process rules, manufacturing routes), and production management model (system limitations and constraint relationship) in process designer. According to the BOM provided by design apartment, the product relational resource should be put into the process designer, and the work-piece of product should produce the product tree. Before simulation operation, all the digital models must be placed into the desired position to achieve the precise positioning of the model in process simulation by relocating command. After the positioning has been calculated, the results are shown in Fig. 3.

According to "Auto Grasp" and "Grasp Wizard", the grasp operation is achieved. The operators movements are achieved by defining the move route, and the direction and 


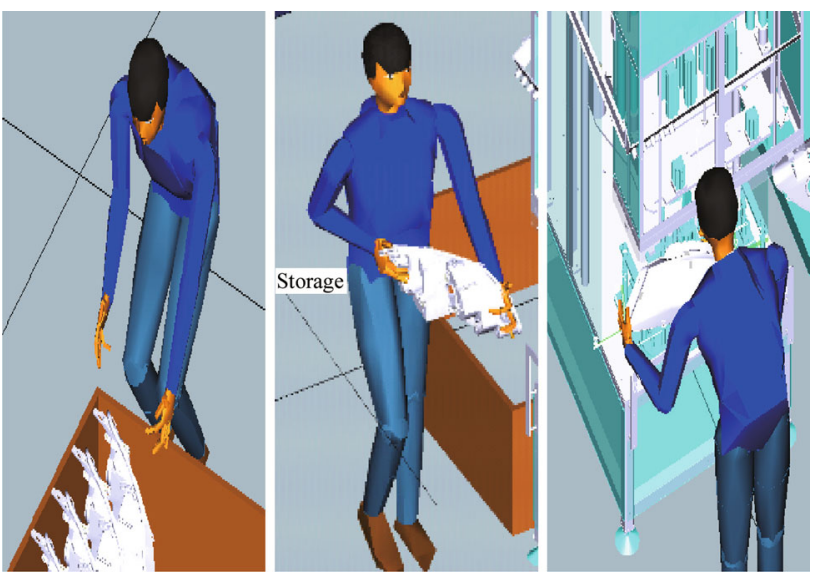

Fig. 4 Posture of operator

posture of operators are also defined by making use of path editing. Human postures and joint jog are used to achieve the modification of human operation. The work-piece is located by using the place object and the simulation commissioning is achieved by using the operation men. Figure 4 is the running UI.

\section{Simulation analysis and optimization}

After simulation, the Gantt chart of five workstations in this U-shaped production line can be obtained by adjusting the operating time of five elements, as shown in Fig. 5.
To choose the function option of ergonomics analysis (human, ergonomics, analysis setup) and set the parameters, the related analysis reports can be output by clicking the option of OWAS or BSHA. To operator 1, for example, the BSHA report is shown in Fig. 6, and the OWAS report is shown in Fig. 7. The action among operators in five workstations is similar.

The simulation results show the posture grade of operator 1 is 3 , which means that his body might be injured. According to BSHA reports, the ratio of load and the maximum load of his left and right hands reach $70 \%$ during operation. It is necessary that the production line program needs to be modified. The low storage point with the machine placed height leads to the poor posture. Taking into account the actual situation of production, it is more reasonable to increase the height about $50 \mathrm{~cm}$ of the storage point and workstation 1 . As a result, the posture of operators has been improved very well, and reports of BSHA and OWAS are shown in Figs. 8 and 9.

This paper provided the optimization of workstation 1 and posture of operator 1 . In addition, it is necessary to analyze and optimize the other workstations, and get the whole optimization solution of this production line.

\section{Conclusions}

This paper not only presents a new strategy for ergonomics, but also provides a new evaluation method for the planning of production line by making use of computer-aided

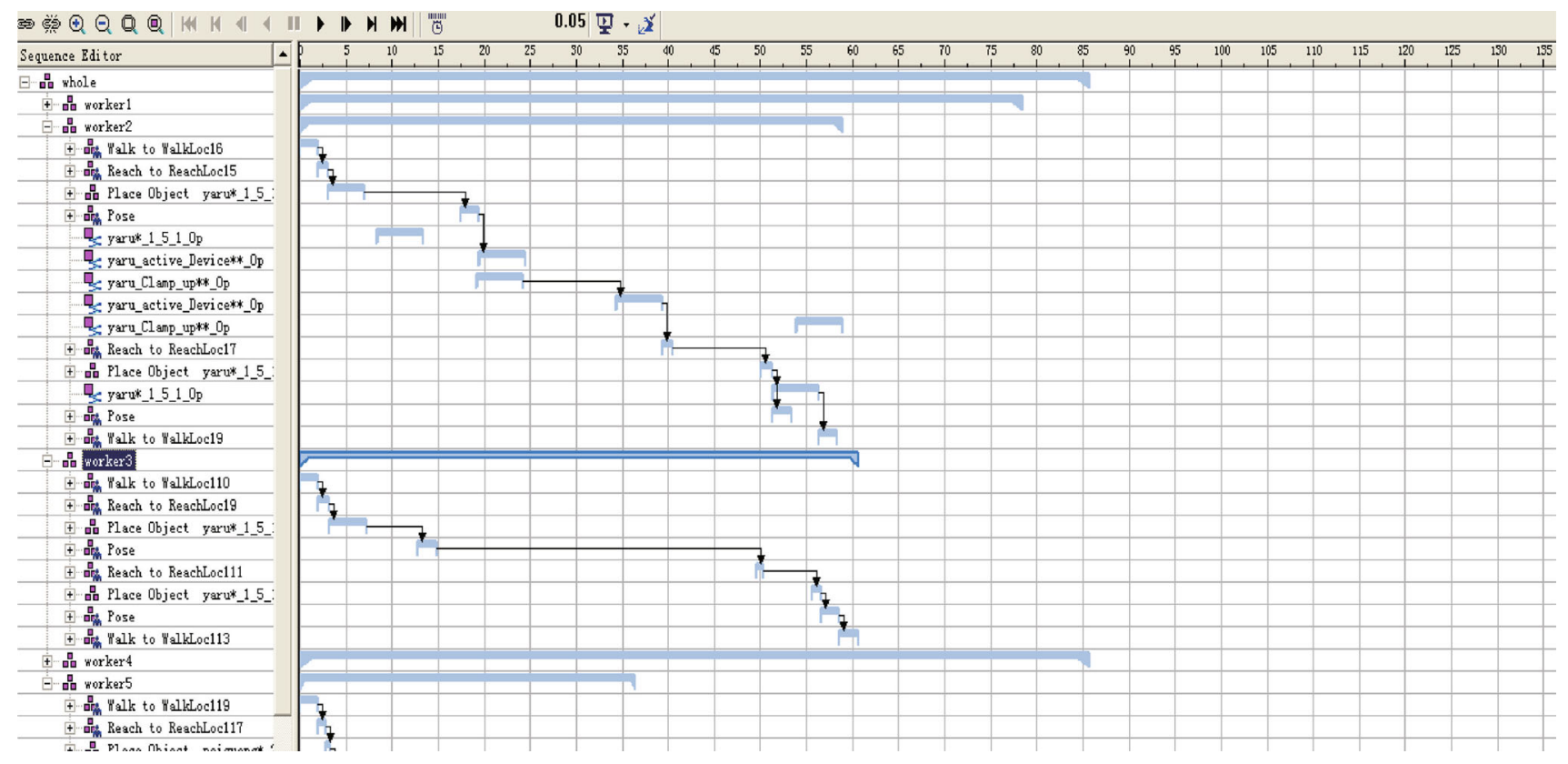

Fig. 5 Gantt chart of ergonomics simulation 


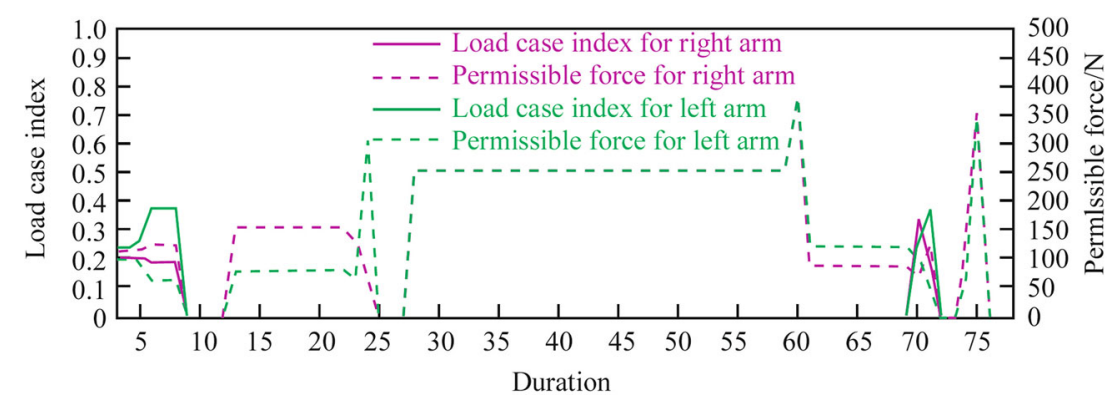

Fig. 6 BSHA report of operator 1

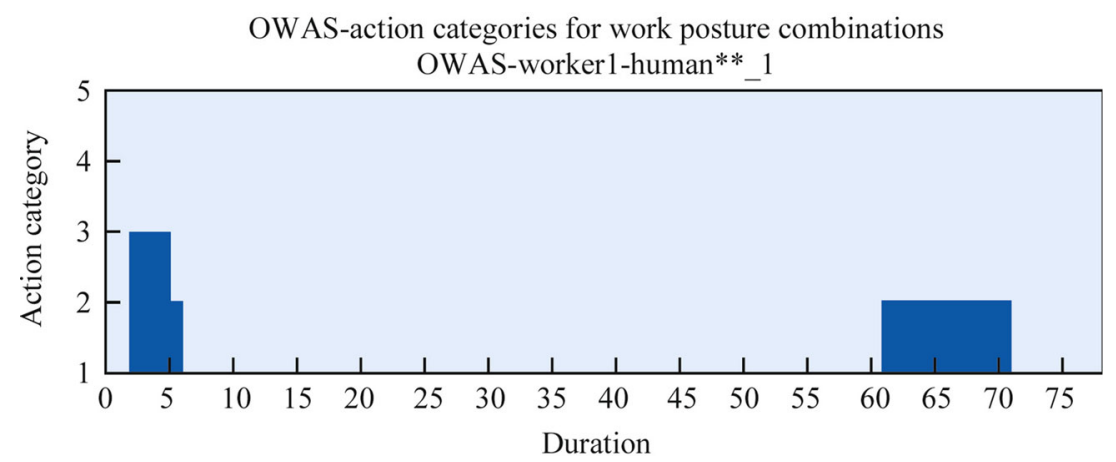

Fig. 7 OWAS report of operator 1

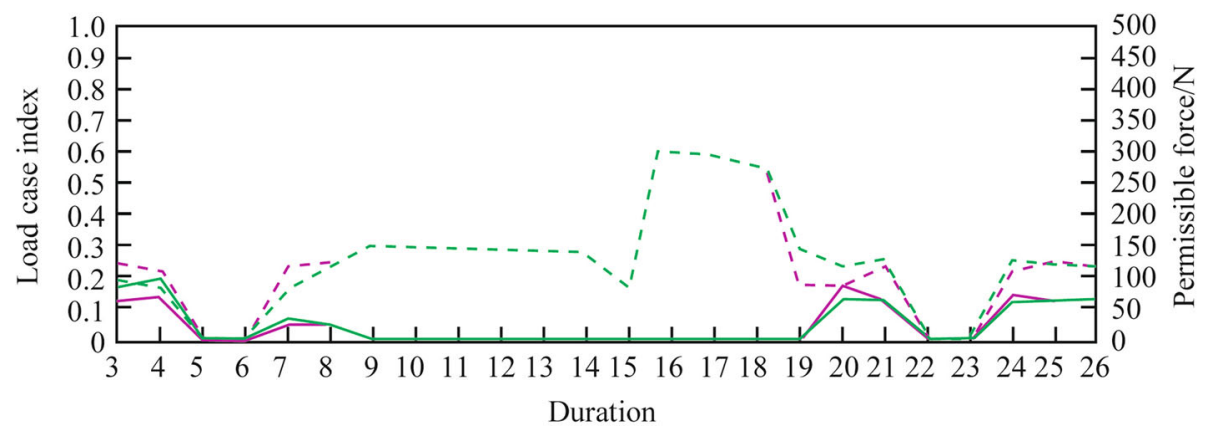

Fig. 8 BSHA report of operators

OWAS-action categories for work posture combinations OWAS-worker1-human**_1

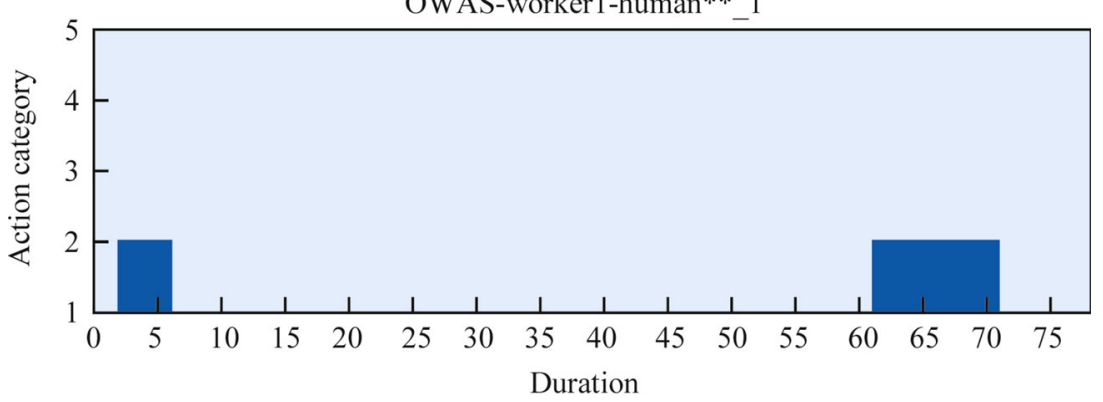

Fig. 9 OWAS report of operators 
software of process simulation and process designer which can be used to achieve the simulation and analysis of ergonomics. However, all simulation softwares are based on a special database or knowledge base. The human body model of process simulation does not fully match the actual body features of Chinese people. Thus, the feasibility of the BSHA report still needs to be discussed and tested further. Moreover, there are great amount of work to modify the correction posture of operators in process simulation. Therefore to establish the resource bases of realistic body posture is the key to achieve simulation and optimization for ergonomics.

Acknowledgements This work was supported by the Science Research Program of Shanghai Science and Technology Commission (Grant No.11dz1121002).

\section{References}

1. Yang M, Yi MD (2009) Ergonomics simulation and application in virtual assembly based on DELMIA. Agric Dev Equip 7:12-16

2. Qin CJ, Zhu GT (2000) Digital humans and internet collaboration in digital manufacturing. J Syst Simul 12:204-207

3. Shi TY, Zhang H, Zhu ZH (2005) Study on the application of ergonomics in the digitalized factory. Modul Mach Tool Autom Manuf Tech 9:18-20

4. Määttä T (2007) Human virtual environments in machinery safety analysis and participatory ergonomics. Hum Factors Ergon Manuf 17(5):435-443

5. Rivilis I, van Eerd D, Cullen K et al (2008) Effectiveness of participatory ergonomic interventions on health outcomes. Appl Ergon 39(3):342-358

6. Vink P, Peeters M, Grundemann RWM et al (1995) A participatory ergonomics approach to reduce mental and physical workload. Int J Ind Ergon 15(5):389-396

7. Vink P, Koningsveld EA, Molenbroek JF (2006) Positive outcomes of participatory ergonomics in terms of greater comfort and higher productivity. Appl Ergon 37(4):537-546

8. Laitila L (2005) Datormanikinprogram om verktyg vid arbetsplatsutformning. En kritisk studie av programanvändning. Thesis, Luleå Technical University, Lulea

9. Westgaard RH, Vinkel J (1997) Ergonomic intervention research for improved musculoskeletal health: a critical review. Int J Ind Ergon 20(6):463-500
10. Kuorinka I, Forcier L (1995) Work related musculoskeletal disordes (WMSDs): a reference book for prevention. Taylor and Francis, London

11. Wilson JR (1995) Solution ownership in a participative work redesign: the case of a crane control room. Int $\mathrm{J}$ Ind Ergon 15(5):329-344

12. Waters TR, Putz-Anderson V, Garg A et al (1993) Revised NIOSH equation for the design and evaluation of manual lifting tasks. Ergonomics 36(7):749-776

13. Falck AC (2007) Virtual and physical methods for efficient ergonomics risk assessments:a development process for application in car manufacturing. Chalmers University of Technology, Göteborg

14. Bisantz AM, Roth E, Brickman B et al (2003) Integrating cognitive analyses in a large-scale system design process. Int J Hum Comput Stud 58(2):177-206

15. Munck-Ulfsfált U, Falck A, Forsberg A et al (2003) Corporate ergonomics programme at Volvo Car Corporation. Applied Ergonomics 34:17-22

16. Broberg $O$ (2007) Integrating ergonomics into engineering: empirical evidence and implications for the ergonomists. Human Factors and Ergonomics in Manufacturing 17(4):353-366

17. Laine E, Malm T, Latokartano J (2007) Human and industrial robot cooperation: technologies and practical examples. In: Proceedings of the 5th international conference safety of industrial automated systems, pp 397-402, Tokyo, Japan

18. Hackos JT, Redish JC (1998) User and task analysis for interface design. Wiley, New York

19. Stanton N (2006) Hierarchical task analysis: developments, applications, and extensions. Applied Ergonomics 37(1):55-79

20. Vicente KJ (1999) Cognitive work analysis toward safe, productive, and healthy computer-based work. Lawrence Erlbaum, Mahwah

21. Beyer H, Holtzblatt K (1999) Contextual design. Interactions 6:32-42

22. Nielsen J (1993) Usability engineering. Academic Press, Boston

23. Karhu O, Kansi P, Kuorinka I (1977) Correcting working postures in industry: a practical method for analysis. Applied Ergonomics 8(4):199-201

24. Muller MJ, Kuhn S (1993) Participatory design. Commun ACM 36:24-28

25. Chen M, Chen LP (2001) Ergonomics-based human modeling and motion simulation. Mech Sci Technol 20:597-602

26. Luo SJ, Sun SQ, Tang MX et al (2005) Study on computer-aided ergonomics design. J Zhejiang Univ Eng Sci 39(6):805-809 